\title{
ASSESSMENT OF DENTAL ANXIETY AMONG A GROUP OF EGYPTIAN DENTAL STUDENTS
}

\author{
Manar Mohammed ${ }^{*}$ and Yomna S.A. Mohamed*
}

\begin{abstract}
Background: Dental anxiety is a psychological feeling; that can prevent partially or completely a person from receiving dental treatment. Anxious dental patients which include dental students suffer from more dental diseases because they cancel or postpone their appointment to the dentist.

Objective: The purpose of this study was to evaluate the level of dental anxiety prevalent among a group of Egyptian dental students and to compare the anxiety levels reported from female and male dental students .

Subjects and Methods: This cross-sectional study was performed among the $1^{\text {st }}, 2^{\text {nd }}$ (pre-clinical years), $3^{\text {rd }}$ and $4^{\text {th }}$ (clinical years $)$ dental students from Faculty of dentistry, October 6 University in Egypt. Corah's dental scale of anxiety (DAS) questionnaires in English language, was distributed among the entire dental students present at the day planned for the study (188 students, females: 114, males: 74). DAS had four questions assessing the level of anxiousness with a probable maximum achievable score of 20 . For each question five options were available in which scoring was accomplished as $\mathrm{A}=1 ; \mathrm{B}=2 ; \mathrm{C}=3 ; \mathrm{D}=4$ and $\mathrm{E}=5$. No anxiety showed a score between 4 and 8 ,moderate anxiety: 9 and 12, high anxiety between 13 and 14 and severe anxiety(phobia) showed score between 15 and 20 .
\end{abstract}

Results: On Comparing DAS scores between males and females students in $1^{\text {st }}, 2^{\text {nd }}$ as well as $3^{\text {rd }}$ year students; males showed statistically significant lower median DAS scores than females with no significant difference between both gender in the $4^{\text {th }}$ year. As regards all years students, males showed statistically significantly lower median DAS scores than females ( $P$-value $<0.001)$.

Conclusion: Female dental students showed more anxiety levels as compared to male dental students for both pre- clinical and clinical years.

Keywords: Dental anxiety score(DAS); Gender difference; Dental students ; Fear ; pre-clinical; clinical years.

* Lecturer, Department of Pediatric and Community Dentistry; Faculty of Oral and Dental Medicine, October 6 University, Giza, Egypt. 


\section{INTRODUCTION}

Dental anxiety is used as a term to describe fear, anxiety or stress in a dental setting. The prevalence of dental anxiety is usually reported worldwide, ranged between 3.9 and $11 \%$ amonggeneral population ${ }^{(1)}$. Anxiety related to dental treatment is a well-recognized phenomenon that can affect all age groups ,but commonly observed among young adults between 18 and 26 years of age ${ }^{(2)}$.Numerous studies have demonstrated that dental fear is associated with irregular dental visiting and sometimes visiting only when there is a problem rather than for a check-up ; and cancelling or deferring appointments for needed dental treatment ${ }^{(3)}$. Avoidance of dental treatment due to dental anxiety not only positions the oral health of a patient at risk but also poses a severe threat to his general health and the patient can suffer from a number of serious medical complications like septicemia, sinusitis and osteomyelitis of the face ${ }^{(4)}$ .This emotional status can also influence the dentist ,who may become tense and anxious to manage those patients who are known to be difficult and more prone to delay or even cancel their dental appointments $^{(5)}$. There are several theories which could explain the reasons for dental anxiety; among these, unpleasant first dental experience from a non-empathetic dentist appear to represent the major cause of dental anxiety ${ }^{(6)}$. Dental students constitute an important segment of health care providers all over the world. It has been previously stated that patients feel less tense and more comfortable when the dentist treats them with confidence. Therefore, it becomes essential for a dental student to learn about the techniques which can help their patients to overcome their respective dental anxiousness and to be able to rate the patient anxiety level for proper control and management ${ }^{(7)}$.Dental anxiety is defined as a patient's response to stress that is specifically related to dental situations ${ }^{(8)}$,there is a widespread range of scales for psychometric selfassessment which are commonly used for clinical and research purposes to assess fear and dental anxiety. The Corah Dental Anxiety Scale (CDAS) is the most common utilized scale ${ }^{(9)}$.Although dental anxiety has been ranked fifth when it comes to most frequently feared conditions ${ }^{(10)}$; there are limited data present in the literature highlighting dental anxiety level of dental students in Egypt. Hence this cross sectional study was performed to assess the level of dental anxiety existing in the dental students from Faculty of dentistry, October 6 university in Egypt and to compare the anxiety levels existing between female and male dental students.

\section{SUBJECTS AND METHODS}

This cross-sectional study was conducted among the $1^{\text {st }}, 2^{\text {nd }}$ (pre-clinical years), $3^{\text {rd }}$ and $4^{\text {th }}$ (clinical years) dental students of Faculty of dentistry, October 6 University in Egypt. The purpose of the study was explained to the students and their inquiries were answered. An informed consent was taken from all the respondents before participating in the study .A total of 188 students participated in the study; all students were clearly informed about the voluntary nature of their participation and their rights as volunteers to withdraw from this study at any point in time during its course. Questionnaires were answered anonymously by students in which their age and gender were only required

Sample size calculation: A power analysis was designed to have adequate power to apply a 2-sided statistical test of the research question (State). According to the results of Farooq and $\mathrm{Ali}^{(11)}$ in which the prevalence of anxiety among dental students was (10.77\%)- and by adopting a confidence interval of (95\%), a margin of error of $(5 \%)$ with finite population correction; The predicted sample size (n) was a total of (148) cases. Sample size calculation was performed using Epi info for windows version $7.2^{(12)}$.

All students were given $15 \mathrm{~min}$ to answer a preprinted questionnaire. Corah's dental anxiety scale (DAS) was utilized in this study. DAS comprises of four items related to different situations that can occur at a dental clinic. These 
items evaluated various levels of anxiousness. Five answers were presented for each question. Scoring was performed as $\mathrm{A}=1 ; \mathrm{B}=2 ; \mathrm{C}=3 ; \mathrm{D}=4$ and $\mathrm{E}=5$. Option (A) indicated the least level of anxiousness whereas option (E) presented the maximum level of anxiousness. Maximum possible achievable score was 20. Anxiety scoring from DAS is categorized as: 4-8: not anxious; 9-12: moderate anxious; 13-14: high anxious;15-20: severe anxiety (phobia). DAS questionnaire was distributed (in English language) among all dental students from different years at the end of their respective lectures. No attempt was made to obtain the responses of the students who were absent on the day of study (Table 1).

\section{Statistical analysis}

Qualitative data were presented as frequencies and percentages. Numerical data were explored for normality by checking the distribution of data and using tests of normality (Kolmogorov-Smirnov and Shapiro-Wilk tests). DAS scores data showed non-parametric distribution. Data were presented as mean, standard deviation (SD), 95\% Confidence interval for the mean, median and range values. Kruskal-Wallis test was used to compare between different years. Dunn's test was used for pair-wise comparisons when Kruskal-Wallis test is significant. Mann-Whitney U test was used to compare between males and females. Qualitative data were presented as frequencies and percentages. Fisher's Exact test was used to compare between different years. The significance level was set at $\mathrm{P} \leq 0.05$. Statistical analysis was performed with IBM SPSS Statistics for Windows, Version 23.0. Armonk, NY: IBM Corp.

\section{RESULTS}

\section{Demographic data}

The present study was conducted on 188 dental students;74 males (39.4\%) and 114 females (60.6\%). Sixty-eight students (36.2\%) were First year dental
TABLE (1) Norman Corah's dental questionnaire.

1. If you need to visit the dentist tomorrow for a check-up; how would you feel about it?

A. I would look forward to it as a pleasant experience

B. I would not care by one way or the other

C. I would feels light uneasy about it

D. I would be scared that it would be painful or unpleasant

E. I would be extremely afraid of what the dentist would do

2. How do you feel when you are waiting at the dentist's office for your turn on the dental chair?

A. Relaxed

B. A little uneasy

C. Tense

D. Anxious

E. Extremely anxious that I almost feel physically sick and sometimes break out in a sweat

3. How do you feel when the dentist prepares the drill to begin working on your teeth while you are waiting on the dental chair?

A. Relaxed

B. A little uneasy

C. Tense

D. Anxious

E. Extremely anxious that almost feel physically sick and sometimes break out in a sweat

4. How do you feel if you imagine yourself on the dentist's chair to clean your teeth while you are waiting and the dentist is getting out the instruments that need to be used to scrape your teeth around the gums?

A. Relaxed

B. A little uneasy

C. Tense

D. Anxious

E. Extremely anxious that I almost feel physically sick and sometimes break out in a sweat

Scoring the dental anxiety scale (DAS) (this information is not printed on the form that respondents see); $\mathrm{A}=1 ; \mathrm{B}=2 ; \mathrm{C}=3 ; \mathrm{D}=4 ; \mathrm{E}=5$.

Total possible $=20$.

Rating of anxiety: No anxiety :score between 4 and 8 , moderate anxiety: 9 and 12, high anxiety between 13 and 14 and severe anxiety (phobia) score between 15 and 20 
students; $17 \%$ were Second year dental students, $20.2 \%$ were Third year dental students while $26.6 \%$ were Fourth year dental students. The mean (standard deviation) values for age were 19.7(1.4) years with a minimum of 17 and a maximum of 22.5 years old(95\% CI: 19.5 - 19.9 years old).

\section{Total Dental Anxiety Scale (DAS) scores and levels}

The mean (standard deviation) values for DAS score were $12.3 \pm 1.1$ with a minimum of 11 and a maximum of 15 (95\% CI: 12.2 - 12.5). The majority of students had moderate dental anxiety, almost one third of students had high anxiety and only $2.1 \%$ had severe anxiety level (Figure 1).

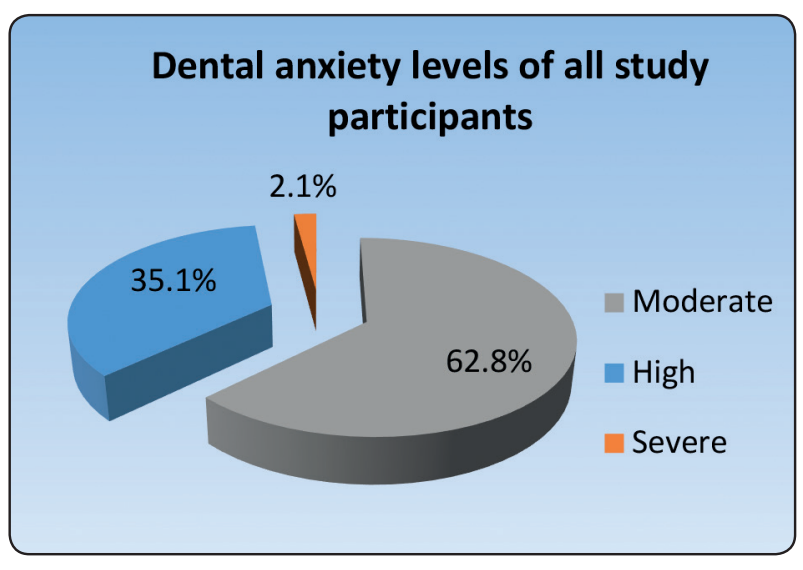

Fig. (1)

\section{Comparison between DAS scores among differ- ent years}

As regards male students; there was a statistically significant difference between DAS scores among different years $(P$-value $<0.001)$. Pair-wise comparisons between different years revealed that there was not y significant difference between first and second year male students; both showed the statistically sig- nificantly highest median DAS scores. There was not significant difference between third and fourth year male students; both showed the statistically significantly lowest median DAS scores.

While in female students; there was also a statistically significant difference between DAS scores among different years $(P$-value $<0.001)$. Pairwise comparisons between different years revealed that first year female students showed the statistically significantly highest median DAS score. There was not significant difference between second and third year female students; both showed statistically significantly lower median DAS scores. Fourth year female students showed the statistically significantly lowest median DAS score.

As regards all students regardless of gender; there was a statistically significant difference between DAS scores among different years $(P$-value $<0.001)$. Pair-wise comparisons between different years revealed that there was not significant difference between first and second year students; both showed the statistically significantly highest median DAS scores. Third year students showed significantly lower median score. Fourth year students showed the statistically significantly lowest median DAS score.

\section{Comparison between DAS scores of males and females}

As regards first, second as well as third year students; males showed statistically significant lower median DAS scores than females $(P$-value $<0.001)$, $(P$-value $<0.001)$ and $(P$-value $<0.001)$, respectively.

While for fourth year students, there was not significant difference between median DAS scores of males and females.

As regards the total sample; males showed statistically significantly lower median DAS scores than females $(P$-value $<0.001)$. 
TABLE (2) Descriptive statistics and results of Kruskal-Wallis test for comparison between DAS scores in males, females as well as the total students at different years

\begin{tabular}{|c|c|c|c|c|c|}
\hline DAS score & $\begin{array}{l}\text { First year } \\
(n=68)\end{array}$ & $\begin{array}{l}\text { Second year } \\
\quad(\mathrm{n}=32)\end{array}$ & $\begin{array}{l}\text { Third year } \\
(\mathrm{n}=38)\end{array}$ & $\begin{array}{l}\text { Fourth year } \\
\qquad(\mathrm{n}=50)\end{array}$ & $P$-value \\
\hline \multicolumn{5}{|l|}{ Males } & \multirow{3}{*}{$<0.001^{*}$} \\
\hline Mean (SD) & $12.2(0.4)^{\mathrm{A}}$ & $12.1(0.3)^{\mathrm{A}}$ & $11.4(0.5)^{\text {в }}$ & $11.1(0.4)^{\text {в }}$ & \\
\hline Median (Range) & $12(12-13)$ & $12(12-13)$ & $11(11-12)$ & $11(11-12)$ & \\
\hline \multicolumn{5}{|l|}{ Females } & \multirow{3}{*}{$<0.001 *$} \\
\hline Mean (SD) & $14(0.5)^{\mathrm{A}}$ & $12.8(0.4)^{\mathrm{B}}$ & $12.4(0.5)^{\mathrm{B}}$ & $11.3(0.5)^{\mathrm{C}}$ & \\
\hline Median (Range) & $14(13-15)$ & $13(12-13)$ & $12(12-13)$ & $11(11-12)$ & \\
\hline \multicolumn{5}{|l|}{ Total } & \multirow{3}{*}{$<0.001^{*}$} \\
\hline Mean (SD) & $13.1(1)^{\mathrm{A}}$ & $12.6(0.5)^{\mathrm{A}}$ & $12.1(0.6)^{\text {в }}$ & $11.2(0.4)^{\mathrm{C}}$ & \\
\hline Median (Range) & $13(12-15)$ & $13(12-13)$ & $12(11-13)$ & $11(11-12)$ & \\
\hline
\end{tabular}

*: Significant at $P \leq 0.05$, Different superscripts in the same row are statistically significantly different

TABLE (3) Descriptive statistics and results of Mann-Whitney U test for comparison between DAS scores in males and females of each year as well as the total sample

\begin{tabular}{|c|c|c|c|}
\hline DAS score & $\begin{array}{c}\text { Males } \\
(\mathrm{n}=68)\end{array}$ & $\begin{array}{l}\text { Females } \\
(\mathrm{n}=32)\end{array}$ & $P$-value \\
\hline \multicolumn{3}{|l|}{ First year } & \multirow{3}{*}{$<0.001 *$} \\
\hline Mean (SD) & $12.2(0.4)$ & $14(0.5)$ & \\
\hline Median (Range) & $12(12-13)$ & $14(13-15)$ & \\
\hline \multicolumn{3}{|l|}{ Second year } & \multirow{3}{*}{$<0.001 *$} \\
\hline Mean (SD) & $12.1(0.3)$ & $12.8(0.4)$ & \\
\hline Median (Range) & $12(12-13)$ & $13(12-13)$ & \\
\hline \multicolumn{3}{|l|}{ Third year } & \multirow{3}{*}{$<0.001^{*}$} \\
\hline Mean (SD) & $11.4(0.5)$ & $12.4(0.5)$ & \\
\hline Median (Range) & $11(11-12)$ & $12(12-13)$ & \\
\hline \multicolumn{3}{|l|}{ Fourth year } & \multirow{3}{*}{0.175} \\
\hline Mean (SD) & $11.1(0.4)$ & $11.3(0.5)$ & \\
\hline Median (Range) & $11(11-12)$ & $11(11-12)$ & \\
\hline \multicolumn{3}{|l|}{ Total } & \multirow{3}{*}{$<0.001^{*}$} \\
\hline Mean (SD) & $11.8(0.6)$ & $12.7(1.1)$ & \\
\hline Median (Range) & $12(11-13)$ & $13(11-15)$ & \\
\hline
\end{tabular}

*: Significant at $P \leq 0.05$
TABLE (4) Mean anxiety level score reported by dental students of various countries.

\begin{tabular}{|l|c|c|}
\hline \multicolumn{1}{|c|}{ Study } & Country & $\begin{array}{c}\text { Mean anxiety } \\
\text { level score }\end{array}$ \\
\hline McGrath and Bedi $^{(13)}$ & Britain & 9.3 \\
\hline Al Omari and Al Omari ${ }^{(14)}$ & Jordan & 11.2 \\
\hline Imran Farooq and Saqib Ali ${ }^{(11)}$ & Pakistan & 12.5 \\
\hline This study & Egypt & 12.3 \\
\hline
\end{tabular}

\section{DISCUSSION}

Dental anxiety is a psychological feeling; that can prevent partially or completely a person from receiving dental treatment. Anxious dental patients which include dental students suffer from more dental diseases because they usually delay or cancel their visit to the dentist, which subsequently complicate their oral health status ${ }^{(15)}$. Therefore, an understanding of the level of dental anxiety amongst dental students will provide an idea about how this phenomenon significantly influences the abilities of future dental professionals to effectively manage their patients. Our study comprised 188 students, 74 males (39.4\%) and 114 females (60.6\%)which 
was in accordance with various studies that have reported more females tend to choose dentistry as a career than males ${ }^{(16,17)}$, This could be the reason for high response rate reported by females and this trend could have well influenced this study results. Another factor that must be taken into consideration when supposing that females are more anxious dentally is the conventional part of males in most of the societies, due to which they avoid revealing their entire feelings while females usually describe their anxieties completely. ${ }^{(18)}$

In this study, the majority of students had moderate dental anxiety (62.8\%), almost one third of students had high anxiety and only $2.1 \%$ had severe anxiety level the mean DAS score was 12.3 which was comparable to the mean anxiety level reported by dental students from Pakistan(12.5) , however in our study Egyptian dental students were more dentally anxious when compared to other countries(Table 4) ${ }^{(19)}$. Previous studies proved that females are more dentally fearful than males ${ }^{(20)}$ which was found to be in accordance with our study in which females dental students showed higher DAS score(14) when compared to males dental students(12.2), this could be explained as females are more reactive than males to certain stimulus like fear of needle ${ }^{(21)}$, which could be the reason of higher anxiety level of females. Also Pierce and Kirkpatrick, 1992 ${ }^{(2)}$ showed that males tend to hide their fears due to their conservative gender role. The most accepted explanation may be related to neuroticism that has been reported higher in females in several previous studies ${ }^{(23,}$ 24), which expressed by being anxious, angry and jealous. Senior students in this study showed less mean DAS which may be due to increased level of dental education and clinical experience, which agreed with Kirova,2011 ${ }^{(25)}$ who found that dental students have high anxiety at the beginning of their training than its end; also the constant exposure to clinical procedure becomes more when the students move from pre-clinical to clinical years therefore it becomes reasonable to anticipate that dental anxiety in dental students decreases with the gradual progress of their education and clinical exposure ${ }^{(26)}$. Another possibility for the decline in dental anxiety with proceeding dental education could be the fact that the repetitive clinical exposure desensitizes the traumatic childhood experience of younger dental students, making them more confident when they are accomplishing any dental procedure ,these results were consistent with the findings of other previous studies $^{(11-27-28) \text {. }}$

\section{CONCLUSIONS AND RECOMMENDATIONS}

Dental students, especially those in the preclinical years were more anxious than dental students in the clinical years, also female dental students were more dentally anxious than male dental students $(\mathrm{P}<0.001)$. Counseling sessions by trained professionals at an early stage of dental training could be helpful in improving the anxiety levels for severely anxious students.

Future studies to observe the difference in the anxiety levels with the general population in Egypt as well further studies to investigate the particular stimulus of dental anxiety among dental students .Finally ,similar studies should be performed in different faculties of dentistry in Egypt to attain dental anxiety levels at a national level.

\section{REFERENCES}

1. Vermaire, J. H., Houtem, C. M., Ross, J. N. \& Schuller, A. A. The burden of disease of dental anxiety: generic and disease-specific quality of life in patients with and without extreme levels of dental anxiety. Eur. J. Oral. Sci. 124, 454-458 (2016).

2. Locker, D., Thomson, W. M. \&Poulton, R. Onset of and patterns of change in dental anxiety in adolescence and early adulthood: a birth cohort study. Community Dent. Health 18, 99-104 (2001).

3. Armfield JM, Spencer AJ, Stewart JF. Dental fear in Australia: who's afraid of the dentist? Aus Dent J 2006; 51:78-85. 
4. Mehrstedt M, John TM, Sven T, Micheelis W. Oral health related quality of life in patients with dental anxiety. Comm Dent Oral Epidemiol 2007;35(5):357-63.

5. Corah NL. Dental anxiety. Assessment, reduction and increasing patient satisfaction. Dent Clin North Am 1988; 32: 779-790.

6. Storjord, H. P., Teodorsen, M. M., Bergdahl, J., Wynn, R. \& Johnsen, J. A. Dental anxiety: a comparison of students of dentistry, biology, and psychology. J. Multidiscip. Healthc. 7, 413 (2014).

7. Ten Berge M, Veerkamp J, Hoogstraten J. Dentist's behaviour in response to child dental fear. J Dent Child 1999;66:36-40.

8. Corah NL, Gale EN, Illig SJ. Assessment of a dental anxiety scale. J Am Dent Assoc1978; 97: 816-819.

9. Corah NL. Development of a dental anxiety scale. J Dent Res 1969; 48: 596.

10. Agras S, Sylvester D, Oliveau D. The epidemiology of common fears and phobia. Compr Psychiatry 1969; 10:151-6.

11. Farooq I and Ali S. "A cross sectional study of gender differences in dental anxiety prevailing in the students of a Pakistani dental college." The Saudi Journal for Dental Research 6.1 (2015): 21-25.

12. Dean, A. G., et al. "Epi Info ${ }^{\mathrm{TM}}$, a database and statistics program for public health professionals." CDC, Atlanta, GA, USA (2011).

13. McGrath C, Bedi R. The association between dental anxiety and oral health related quality of life in Britain. Comm Dent Oral Epidemiol 2004;32:67-72.

14. Al-Omari WM, Al-Omiri MK. Dental anxiety among university students and its correlation with their field of study. J Appl Oral Sci 2009;17:199-203.

15. Kesim S., Unalan, D., Esen, C. \& Ozturk, A. The relationship between periodontal disease severity and state-trait anxiety level. J. Pak. Med. Assoc. 62, 1304-1308 (2012).
16. Weaver RG, Haden NK, Valachovic RW. U.S. dental school applicants and enrollees: a ten-year perspective. J Dent Educ 2000;64(12):867-70. 18.

17. Brand AA, Chikte UME. Choosing dentistry as a careerpart 1: a comparison of student motives. J Dent Assoc South Africa 1992;47(11):469-73.

18. Peretz B, Rosenblum A, Zadik D. Stress levels and related variables among dental students in Jerusalem, Israel. Eur J Dent Educ 1997;1:162-6.

19. Masood AS, Anila K. Over dental anxiety problems among university students: perspective from Pakistan. J Coll Phys Surg Pak 2011;21(4):237-8.

20. Horst TG, Wit DE. Review of behavioural research in dentistry 1987-1992: dental anxiety, dentist-patient relationship, compliance and attendance. Int Dent J 1993;43:265-78.

21. Holtzman JM, Berg RG, Mann J, Berkey DB. The relationship of age and gender to fear and anxiety in response to dental care. Spec Care Dent 1997;17:82-7.

22. Pierce KA, Kirkpatrick DR. Do men lie on fear surveys? Behav Res Ther 1992;30:415-8.

23. Stecher T. Well-being in an academic environment. Med Educ 2004;38:465-78.

24. Freeman R. Communicating effectively: some practical suggestions. Br Dent J 1999;187:240-4.

25. Kirova GD. Dental anxiety among dental students. J IMAB 2011; 17: 2.

26. Peretz B, Mann J. Dental anxiety among Israel dental students: a 4- year longitudinal study. Eur J Dent Educ 2000;4(3):133-7.

27. Acharya S, Sangam DK. Dental anxiety and its relationship with self perceived health locus of control among Indian dental students. Oral Health Prev Dent 2010;8(1):9-14.

28. Reeve PE, Watson CJ. An exploration of the attitudes, personality and performance of dental students. Med Educ 1985; 19:226-37. 